\title{
Identification of internal control genes for quantitative polymerase chain reaction in mammary tissue of lactating cows receiving lipid supplements
}

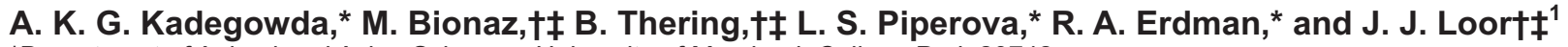 \\ *Department of Animal and Avian Sciences, University of Maryland, College Park 20742 \\ †Mammalian NutriPhysioGenomics, Department of Animal Sciences, and \\ ‡Division of Nutritional Sciences, University of Illinois, Urbana 61801
}

\section{ABSTRACT}

Dietary lipid supplements affect mammary lipid metabolism partly through changes in lipogenic gene expression. Quantitative PCR (qPCR) is a sensitive, reliable, and accurate technique for gene expression analysis. However, variation introduced in qPCR data by analytical or technical errors needs to be accounted for via normalization using appropriate internal control genes (ICG). Objectives were to mine individual bovine mammary microarray data on $>13,000$ genes across 66 cows from 2 independent studies to identify the most suitable ICG for qPCR normalization. In addition to unsupplemented control diets, cows were fed saturated or unsaturated lipids for $21 \mathrm{~d}$ or were infused with supplements (butterfat, conjugated linoleic acid mixture, long-chain fatty acids) into the abomasum to modify milk fat synthesis and fatty acid profiles. We identified 49 genes that did not vary in expression across the 66 samples. Subsequent gene network analysis revealed that 22 of those genes were not co-regulated. Among those COPS7A, CORO1B, DNAJC19, EIF3K, EMD, GOLGA5, MTG1, UXT, MRPL39, GPR175, and $M A R V E L D 1$ (sample/reference expression ratio $=1 \pm$ 0.1 ) were selected for PCR analysis upon verification of goodness of BLAT/BLAST sequence and primer design. Relative expression of B2M, GAPDH, and $A C T B$, previously used as ICG in bovine mammary tissue, was highly variable $(0.9 \pm 0.6)$ across studies. Gene stability analysis via geNorm software uncovered MRPL39, GPR175, UXT, and EIF3K as having the most stable expression ratio and, thus, suitable as ICG. Analysis also indicated that use of 3 ICG was most appropriate for calculating a normalization factor. Overall, the geometric average of MRPL39, UXT, and EIF3K is ideal for normalization of mammary qPCR data in studies involving lipid supplementation of dairy cows. These novel ICG could be used for normalization in similar

Received August 26, 2008.

Accepted December 13, 2008.

${ }^{1}$ Corresponding author: jloor@uiuc.edu studies as alternatives to the less-reliable $A C T B, G A P$ $D H$, or B2M.

Key words: internal control gene, transcriptomics, milk fat

\section{INTRODUCTION}

Large-scale transcript analysis of lactating mouse mammary tissue has shown that regulation of mammary lipid synthesis occurs to a large extent at the level of mRNA expression (Rudolph et al., 2007). Although the molecular mechanisms by which dietary fatty acids regulate ruminant mammary lipogenic gene expression are not completely established, there is evidence of a role for transcriptional regulators and their target genes at least in bovine (Peterson et al., 2004; Harvatine and Bauman, 2006). The advent of bovine microarray (Loor et al., 2007) has enabled large-scale evaluation of mRNA expression in tissues due to nutrition or physiological state (Loor et al., 2005, 2006). Use of this technology promises to substantially increase our knowledge of transcriptional adaptations in bovine tissues.

Despite the advantages of microarrays, quantitative reverse transcription-PCR (qPCR) remains the method of choice for evaluation of mRNA expression as it is the most sensitive, reliable, and accurate technique available for gene expression analysis. Central to the applicability of qPCR is the fact that variation introduced because of analytical or technical errors during the procedure should be accounted for via normalization. Use of appropriate internal control genes (ICG) is the most reliable method currently used for data normalization (Vandesompele et al., 2002) because it can account for differences due to initial quantity of RNA, RNA handling, and variation in kinetics of the reverse transcription reaction. The selected ICG should not vary due to the type of cells or tissues or respond differently to treatments (Vandesompele et al., 2002). Thus, proper selection and evaluation of ICG is critical to avoid additional variation in the data.

There is no consensus on suitable ICG for studies of dietary lipid effects on ruminant mammary 
transcriptomics. Most recent studies (via Northern blot or qPCR) have relied on individual ICG (commonly known as housekeeping genes) such as $\beta$-actin (ACTB; Peterson et al., 2003, 2004), glyceraldehyde3-phosphate dehydrogenase (GAPDH; Baumgard et al., 2002; Sorensen et al., 2008), and cyclophilin (i.e., peptidylprolyl isomerase A to $\mathrm{H}, P P I A-H$; Bernard et al., 2005) as well as ribosomal proteins (RPS4, RPS28; Piperova et al., 2000; Ahnadi et al., 2002). The geometric mean of $A C T B, \beta-2$-microglobulin $(B 2 M)$, and $18 \mathrm{~S}$ rRNA (Harvatine and Bauman, 2006) or that of $A C T B, G A P D H$, and ubiquitin have been used recently (Farke et al., 2008). However, $A C T B$ and GAPDH were the least suitable or were highly variable ICG among several tested in bovine mammary tissue (Bionaz and Loor, 2007; Piantoni et al., 2008). Furthermore, the use of $18 \mathrm{~S}$ rRNA for normalization is questionable because of its high abundance (Vandesompele et al., 2002).

The specific objective of this study was to identify more-robust ICG for normalization of $\mathrm{qPCR}$ through mining individual mammary tissue microarray data from 2 independent lactating dairy cow studies dealing with lipid supplementation. Pairwise analysis of mRNA expression ratios (Vandesompele et al., 2002) was used to identify potential ICG.

\section{MATERIALS AND METHODS}

\section{RNA Extraction, PCR, and Primer Design and Testing}

Mammary tissue samples $(\mathrm{n}=66)$ from lactating dairy cows infused for $14 \mathrm{~d}$ with butterfat [a source of short- and long-chain fatty acids (LCFA)], LCFA, or a conjugated linoleic acid (CLA) mixture (Kadegowda et al., 2008), samples from cows fed saturated (EB100; Energy Booster 100, MSC, Carpentersville, IL) or unsaturated lipid supplements (fish oil) for $21 \mathrm{~d}$ (Thering et al., 2007), and unsupplemented controls were used in the study. Cows in the first study (Kadegowda et al., 2008) were in early lactation and cows in the second study were in mid lactation (Thering et al., 2007). Mammary tissue was collected via percutaneous biopsy as reported in Bionaz and Loor (2007), immediately frozen in liquid $\mathrm{N}_{2}$, and preserved at $-80^{\circ} \mathrm{C}$ for RNA extraction as described previously (Loor et al., 2005).

Total RNA was extracted from approximately 0.5 $\mathrm{g}$ of tissue using ice-cold Trizol reagent (Invitrogen, Carlsbad, CA). The RNA concentrations were quantified with a NanoDrop ND-1000 spectrophotometer (NanoDrop Technologies, Wilmington, DE) and the quality was evaluated using a 2100 Bioanalyzer (Agilent Technologies, Santa Clara, CA). All samples had RNA integrity number $>6.0$. Genomic DNA was removed by DNase digestion and cleaned using RNeasy Mini
Kit columns (Qiagen, Valencia, CA). A portion of the assessed RNA was diluted to $100 \mathrm{ng} / \mu \mathrm{L}$ using DNaseRNase-free water before cDNA synthesis by reverse transcriptase. Sufficient cDNA was prepared in a single run to perform PCR for all selected genes. Protocol for cDNA synthesis and qPCR are described elsewhere (Bionaz and Loor, 2007). Before starting the qPCR reaction, synthesized cDNA was diluted $1 / 4$ (vol/vol) with free DNase-RNase-free water in experiment 1 , whereas a dilution $1 / 3(\mathrm{vol} / \mathrm{vol})$ was used in experiment 2 . For qPCR, $4 \mu \mathrm{L}$ of diluted cDNA was combined with 6 $\mu \mathrm{L}$ of reaction mixture composed of $5 \mu \mathrm{L}$ of $1 \times \mathrm{SYBR}$ Green master mix (Applied Biosystems), $0.4 \mu \mathrm{L}$ each of $10 \mu \mathrm{M}$ forward and reverse primers and $0.2 \mu \mathrm{L}$ of DNase-RNase-free water in a MicroAmp Optical 384well reaction plate (Applied Biosystems). For qPCR, each sample was run in triplicate and a 6-point relative standard curve plus the non-template control were used. The 4-fold-dilution standard curve was made using cDNA synthesized from a pooled RNA of all the samples. The reactions were performed in an ABI Prism 7900 HT SDS instrument (Applied Biosystems) using the following conditions: $2 \mathrm{~min}$ at $50^{\circ} \mathrm{C}, 10 \mathrm{~min}$ at $95^{\circ} \mathrm{C}, 40$ cycles of $15 \mathrm{~s}$ at $95^{\circ} \mathrm{C}$, and $1 \mathrm{~min}$ at $60^{\circ} \mathrm{C}$. Despite different dilutions of cDNA, samples from both experiments were run in the same PCR plate.

The presence of a single PCR product was verified by the dissociation protocol using incremental temperatures to $95^{\circ} \mathrm{C}$ for $15 \mathrm{~s}$ plus $65^{\circ} \mathrm{C}$ for $15 \mathrm{~s}$. Data were calculated with the 7900 HT Sequence Detection Systems Software (version 2.2.1, Applied Biosystems). Primer Express 3.0 software (Applied Biosystems), optimized for use with Applied Biosystems PCR Systems, was used for primer design using default features, except for amplicon length, which was fixed, when possible, at a minimum of $100 \mathrm{bp}$. Primers were designed across exon junctions when feasible to avoid amplification of genomic DNA. The exon junctions were uncovered by blasting the sequence against the bovine genome (Genome Browser Gateway, 2008). Primers were aligned against publicly available sequences in National Center of Biotechnology Information (National Center of Biotechnology Information, 2008) and University of California Santa Cruz (USCS; Genome Browser Gateway, 2008). Primer features are reported in Table 1 and qPCR performance in Table 2. Before qPCR, primers were tested using the same protocol as for qPCR but without the dissociation step in a $20-\mu \mathrm{L}$ reaction. Part of the qPCR product was run in a $2 \%$ agarose gel stained with ethidium bromide to assess the presence of the product to an expected size and presence of primer-dimer; the remainder was purified using Qiaquick PCR purification kit (Qiagen, Valencia, CA) and sent to sequence at the Core DNA Sequencing Facility of the Roy J. Carver Biotechnology 
Table 1. Accession number, gene symbol, sequence, and amplicon size of genes tested

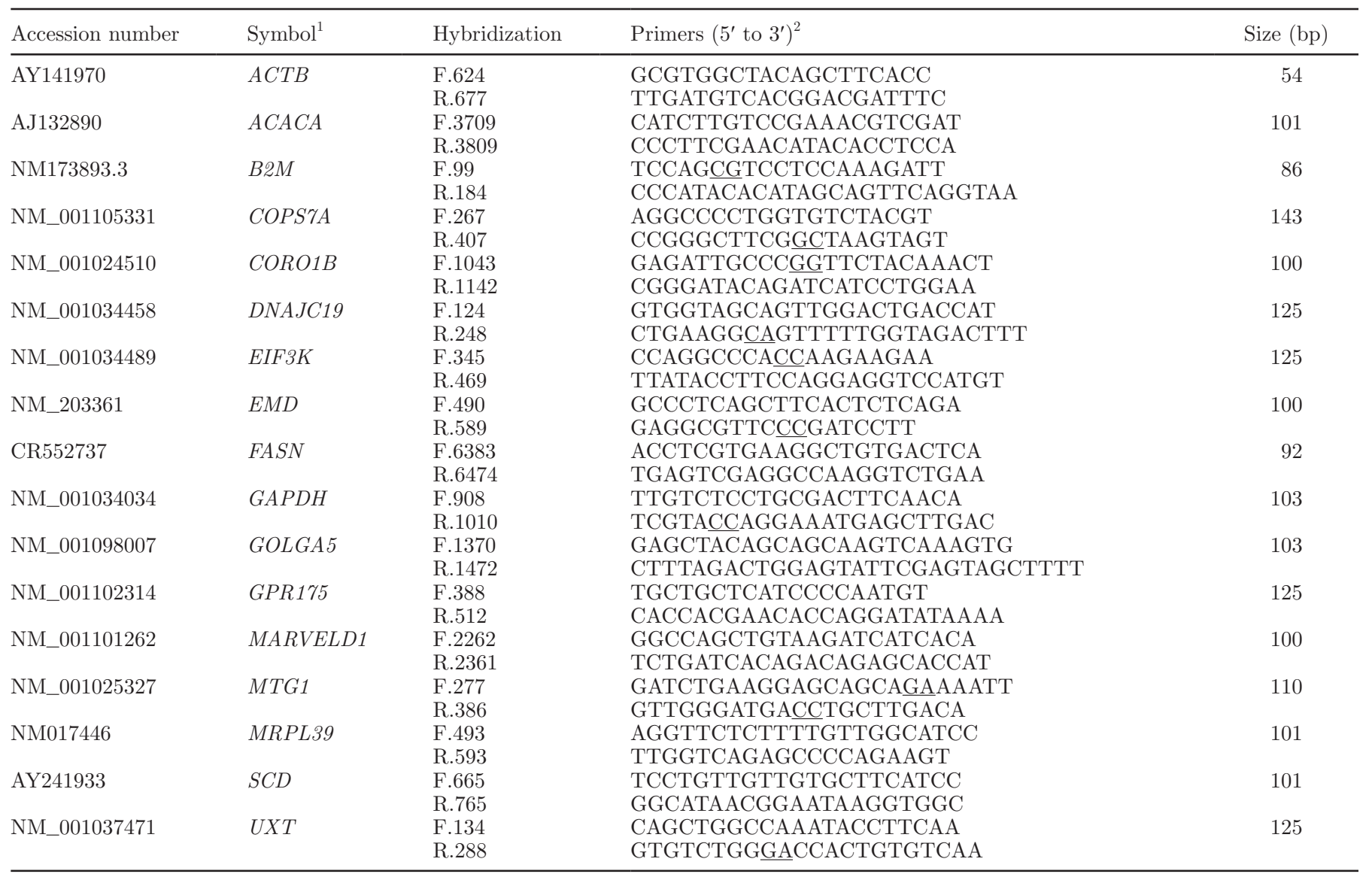

${ }^{1}$ Details of the genes are reported in Table 3.

${ }^{2}$ Exon-exon junctions are underlined.

Center at the University of Illinois, Urbana (data not shown). Only primers with high specificity evaluated by a single band on agarose gel, absence of primerdimer, amplification of the correct cDNA verified by sequencing, and a unique peak in the dissociation curve after qPCR reaction were used.

\section{Selection and Evaluation of ICG}

One hundred thirty-two bovine microarrays in a dye-swap reference design from experiments 1 and 2 were used to identify potential ICG. Description of the platform and protocols for microarray analysis were described previously (Loor et al., 2007). The ICG selection criteria and protocol were described previously (Piantoni et al., 2008; Tramontana et al., 2008) and modified slightly. Briefly, genes with median intensity $>3$ standard deviations (SD) above background were uploaded to GeneSpring GX 7.3 software (Agilent Technologies, Santa Clara, CA) and normalized using
Lowess. Genes were filtered by intensity $>100$ relative fluorescent units (medium-to-large mRNA abundance). A ratio sample/reference of $\sim 1.0$ was used to identify genes with stable expression among samples and reference (pooled RNA from several bovine tissues). In addition to the genes meeting these criteria, 9 previously tested ICG (ACTB, GAPDH, RPS23, RPS9, MTG1, ITGB 4BP, MRPL39, RPS15A, and UXT) in bovine mammary tissue (Bionaz and Loor, 2007) and B2M were selected for subsequent analysis. Subsequently, co-regulation among selected genes was assessed using Ingenuity Pathway Analysis (IPA, Redwood City, CA). This allows the examination of gene networks within large data sets and is based on published relationships among genes across human and rodents. The qPCR analysis was then run for the selected genes (i.e., with absence of co-regulation). Last, analysis of expression ratio stability and optimal number of ICG to calculate the normalization factor (NF) was conducted with geNorm software (Vandesompele et al., 2002). Quanti- 
Table 2. Slope, coefficient of determination of the standard curve $\left(\mathrm{R}^{2}\right)$, efficiency of amplification, and median cycle threshold $(\mathrm{Ct})$ of quantitative reverse transcription PCR in measured transcripts for the internal control genes tested and lipogenic genes

\begin{tabular}{lccccc}
\hline Gene $^{1}$ & Slope $^{2}$ & $\mathrm{R}^{2}$ & $\mathrm{E}^{3}$ & $\mathrm{Ct}^{4}$ & mRNA abundance, ${ }^{5} \%$ \\
\hline COPS7A & -3.137 & 0.998 & 2.08 & 23.22 & 0.1 \\
CORO1B & -3.154 & 0.997 & 2.08 & 22.75 & 0.2 \\
DNAJC19 & -3.323 & 0.989 & 2.00 & 23.06 & 0.4 \\
EIF3K & -3.396 & 0.996 & 1.97 & 19.73 & 0.6 \\
EMD & -3.157 & 0.994 & 2.07 & 21.46 & 0.3 \\
GOLGA5 & -3.202 & 0.995 & 2.05 & 22.73 & 0.1 \\
GPR175 & -3.106 & 0.998 & 2.10 & 23.32 & 0.1 \\
MARVELD1 & -3.431 & 0.995 & 1.96 & 21.54 & 0.3 \\
MRPL39 & -3.137 & 0.993 & 2.08 & 23.49 & 0.1 \\
MTG1 & -3.302 & 0.996 & 2.01 & 23.56 & 3.0 \\
UXT & -3.179 & 0.998 & 2.06 & 23.94 & 2.5 \\
ACTB & -3.20 & 0.998 & 2.05 & 18.8 & 0.2 \\
B2M & -3.40 & 0.994 & 1.97 & 16.9 & 20.5 \\
GAPDH & -3.33 & 0.998 & 2.00 & 20.5 & 23.0 \\
ACACA & -2.993 & 0.998 & 2.16 & 21.48 & \\
FASN & -3.239 & 0.998 & 2.04 & 17.01 & \\
SCD & -3.243 & 0.995 & 2.03 & 16.87 & \\
\hline
\end{tabular}

${ }^{1}$ Details of the genes are reported in Table 3 .

${ }^{2}$ Slope of the 6-point standard curve.

${ }^{3}$ Efficiency of amplification $\left[\mathrm{E}=10^{(-1 / \text { slope })}\right]$.

${ }^{4} \mathrm{Ct}=$ median cycle threshold which is defined as the number of cycles required for the fluorescent signal to cross the threshold (i.e., exceed background level); Ct levels are inversely proportional to the amount of target nucleic acid in the sample (i.e., the lower the $\mathrm{Ct}$ level the greater the amount of target nucleic acid in the sample).

${ }^{5} \mathrm{mRNA}$ abundance is calculated as percentage of $\left(1 / \mathrm{E}^{\Delta \mathrm{Ct}}\right)$ specific gene in the sum $\left(1 / \mathrm{E}^{\Delta \mathrm{Ct}}\right)$ all genes.

tative PCR also was performed on the commonly used ICG ACTB, GAPDH, and B2M. These data were used in the pairwise analysis along with the selected ICG.

The applicability of those ICG with greater expression ratio stability as well as $A C T B, G A P D H$, and $B 2 M$ was tested by conducting $\mathrm{qPCR}$ on classical genes associated with fatty acid metabolism such as acetyl-CoA carboxylase- $\alpha(A C A C A)$, fatty acid synthase $(F A S N)$, and stearoyl-CoA desaturase $(S C D)$ (Table 3$)$.

\section{Statistical Analysis}

Raw qPCR (i.e., nonnormalized) data of ICG and normalized data of lipogenic genes were analyzed using the MIXED procedure (SAS Inst., Cary, NC). The statistical analysis was conducted separately for each experiment. Fixed effects were treatments and cow was the random effect. Correlations among genes were run using the CORR procedure of SAS.

Table 3. Gene symbol, description or name, and main biological function and process ${ }^{1}$

\begin{tabular}{|c|c|c|}
\hline Symbol & Name & Biological function and biological process \\
\hline$B 2 M$ & $\beta$-2-Microglobulin & Protein binding, immune response \\
\hline CORO1B & Coronin, actin binding protein, 1B & Actin binding, protein binding \\
\hline DNAJC19 & Dnaj (Hsp40) homolog, subfamily C, member 19 & Heat shock protein binding, protein import into mitochondrion \\
\hline EIF3K & Eukaryotic translation initiation factor 3 , subunit $\mathrm{K}$ & Protein binding, ribosome binding, translation initiation activity \\
\hline GOLGA5 & Golgi autoantigen, golgin subfamily a, 5 & ATP binding, Rab GTPase binding, protein tyrosine kinase activity \\
\hline GPR175 & $\mathrm{G}$ protein-coupled receptor 175 & G-protein coupled receptor activity, lipid metabolism, aging \\
\hline MARVELD1 & MARVEL domain containing 1 & Membrane bound protein with unknown function \\
\hline$M T G 1$ & $\begin{array}{l}\text { Mitochondrial gtpase } 1 \text { homolog } \\
\text { (Saccharomyces cerevisiae) }\end{array}$ & GTP binding, nucleotide binding \\
\hline MRPL39 & Mitochondrial ribosomal protein L39 & Protein synthesis within the mitochondrion \\
\hline$U X T$ & Ubiquitously expressed transcript & $\beta$-Tubulin binding, microtubule binding, unfolded protein binding \\
\hline
\end{tabular}

${ }^{1}$ Entrez Gene; National Center for Biotechnology Information. 


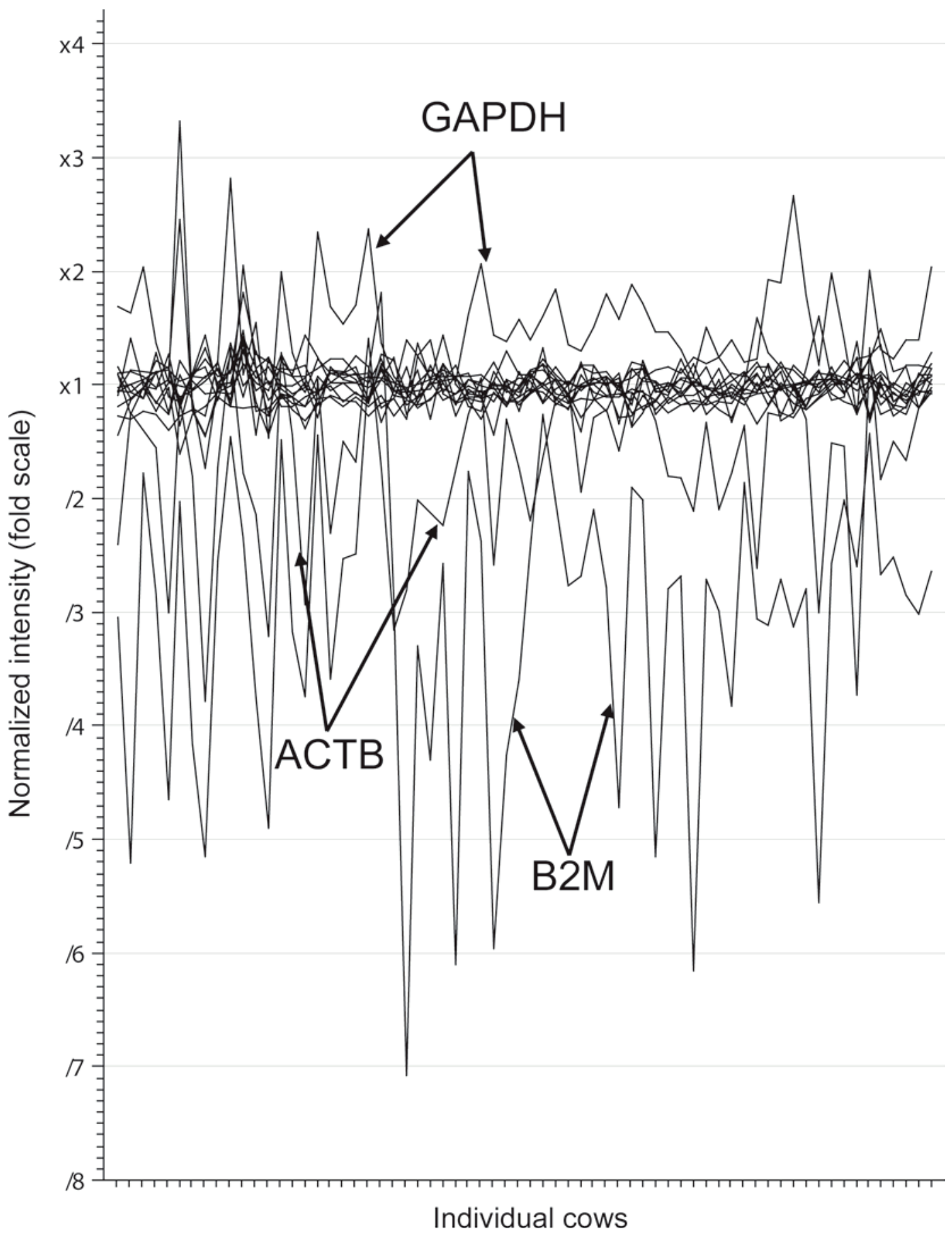

Figure 1. Microarray expression patterns of potential internal control genes as well as $\beta$-actin $(A C T B)$, glyceraldehyde-3-phosphate dehydrogenase $(G A P D H)$, and $\beta$-2-microglobulin $(B 2 M)$, in mammary tissue of cows used for the 2 experiments reported in Materials and Methods. Microarrays were run in a dye-swap-reference design configuration. The figure was generated using GeneSpring GX software (Agilent Technologies, Santa Clara, CA). Loess-normalized ratios of sample mammary RNA/reference RNA are depicted.

\section{RESULTS AND DISCUSSION}

\section{Selection of Potential ICG}

The first criterion for selecting ICG was to identify genes with stable expression across all 66 samples en- compassing 6 different lipid supplements and 2 controls. Using this initial filtering step, we identified 49 transcripts in 60 out of 66 samples with expression ratio of $1.0 \pm 0.2$ among $>10,000$ annotated transcripts on the microarray. Of these transcripts, 10 were excluded from 


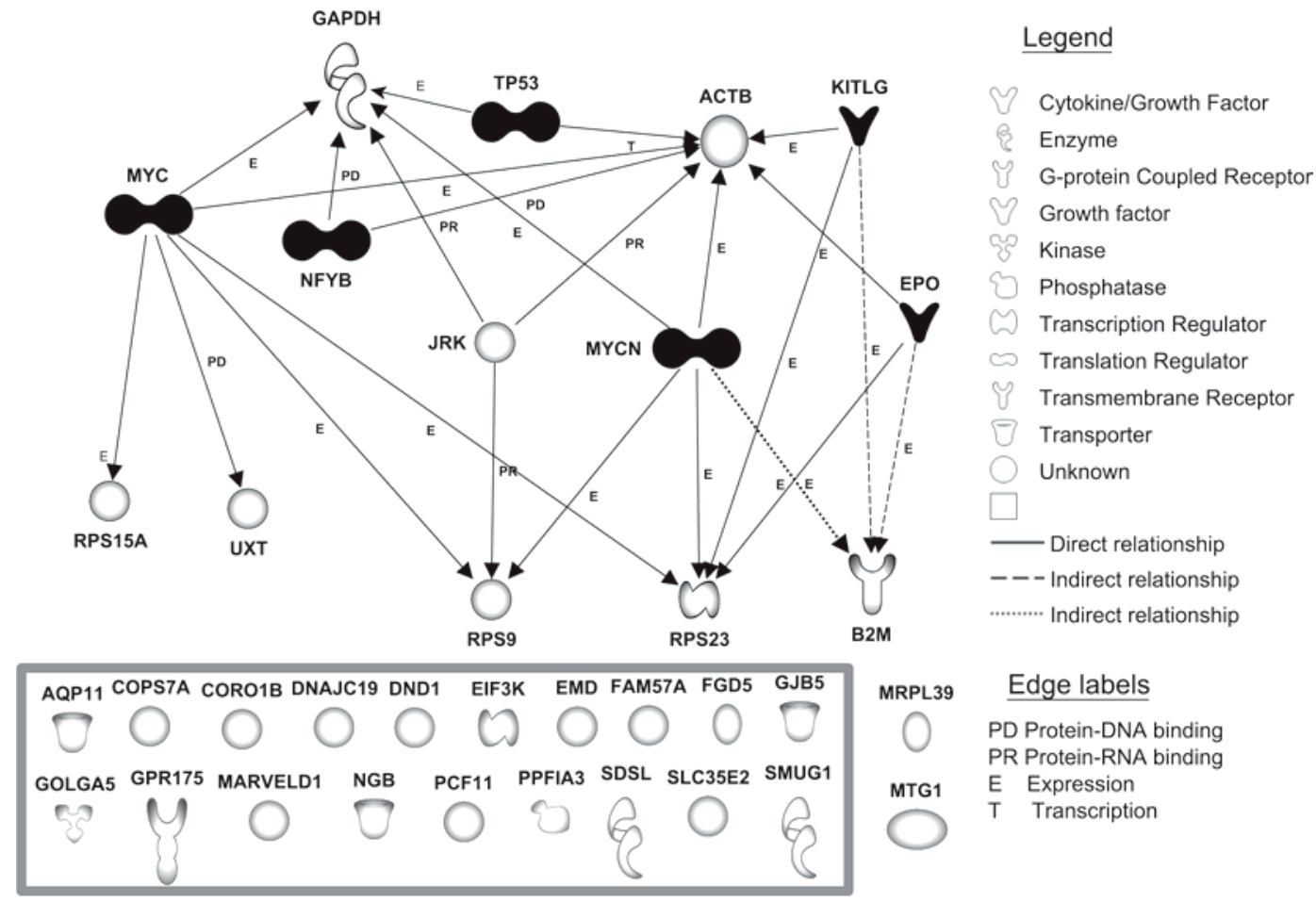

(1) 2000-2009 Ingenuity Systems, Inc. All rights reserved.

Figure 2. Co-regulation analysis using Ingenuity Pathway Analysis among the 39 potential internal control genes (ICG). Enclosed in the box are the 19 genes with the highest stability as judged by the ratio of sample/reference uncovered by microarray and without currently known co-regulation. Also shown are putative co-regulations among $\beta$-actin $(A C T B)$, glyceraldehyde-3-phosphate dehydrogenase $(G A P D H)$, and $\beta$-2microglobulin $(B 2 M)$, as well as 6 genes previously tested as ICG in bovine mammary tissue during the entire lactation cycle [mitochondrial ribosomal protein L39 (MRPL39), mitochondrial GTPase 1 homolog (Saccharomyces cerevisiae (MTG1), ribosomal proteins 9 (RPS9), 15A (RPS15A), and 23 (RPS23), and ubiquitously expressed transcript (UXT); Bionaz and Loor, 2007]. The additional 11 potential ICG found to be highly stable by microarray analysis had co-regulations and were not used for further analysis. These co-regulation networks have been omitted from the figure to highlight co-regulations among previously used ICG. The ICG tested are shaded in gray, whereas potential upstream co-regulators are shaded in black.

subsequent steps as annotation was not available or the annotation of oligonucleotides on the microarray could not be verified by BLAST analysis (National Center of Biotechnology Information, 2008); $A C T B, G A P D H$, and $B 2 M$ were not present among the 49 genes. In addition, 8 cyclophilin isoforms (PPIA to $H$ ) represented on the microarray platform were not among the 49 genes (Supplemental Table 1; available online at http://jds. fass.org/content/vol92/issue5/). Of these, only PPIG was close to having stable expression between sample/ reference $(1.0 \pm 0.3)$. The above are among the most commonly used ICG in studies of bovine/caprine mammary lipid synthesis regulation (Peterson et al., 2003; 2004; Bernard et al., 2005; Harvatine and Bauman, 2006; Sorensen et al., 2008). Micoarray data showed that $A C T B, G A P D H$, and $B 2 M$ were highly variable across all samples; that is, the expression ratio averaged $\sim 0.9 \pm 0.6$ (Figure 1) confirming their unreliability for $\mathrm{qPCR}$ normalization as observed previously in nonru- minant tissues (Glare et al., 2002; Vandesompele et al., 2002).

\section{Co-Regulation Analysis}

The second criterion applied was testing for absence of co-regulation; that is, the selected genes should not be regulated through common upstream effectors (e.g., transcription factors) or should not directly regulate each other. This criterion is particularly important when applying the geometric mean approach; that is, use of 2 or more genes to calculate NF, developed by Vandesompele et al. (2002). Network analysis was performed on 39 genes showing stable expression during microarray analysis, 9 previously tested ICG (Bionaz and Loor, 2007), and B2M. Among several regulatory networks, Ingenuity Pathway Analysis revealed co-regulation between commonly used ICG such as $G A P D H, B 2 M$, and $A C T B$ through several transcrip- 

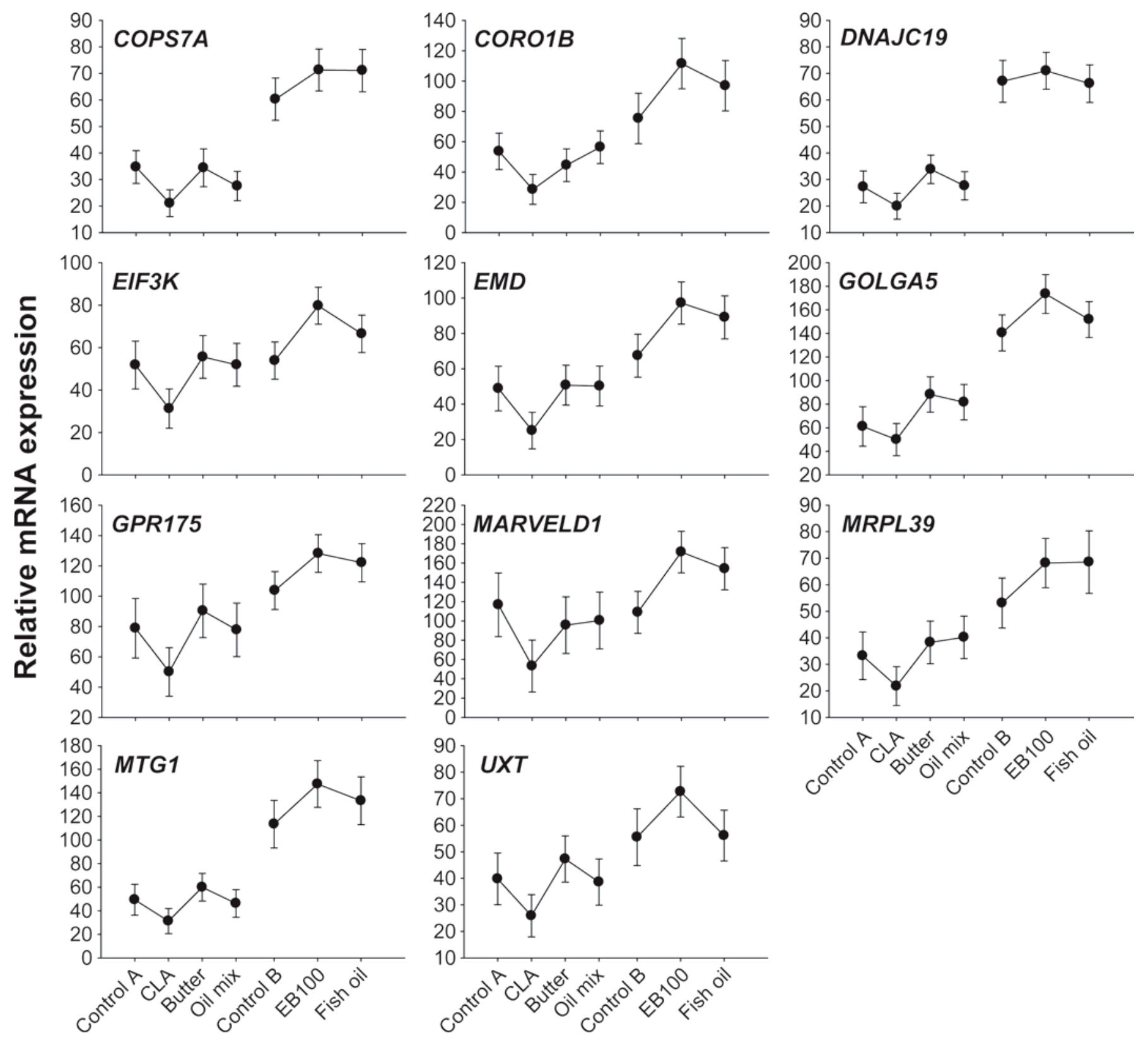

Figure 3. Mammary tissue mRNA expression patterns (mean \pm SEM) of potential internal control genes (ICG) in cows receiving control, lipid supplements into the abomasum [experiment 1; control A, conjugated linoleic acid (CLA), butter, and oil mix], or fed in a TMR [experiment 2; control B, EB100 (Energy Booster 100, MSC, Carpentersville, IL), and fish oill. Data shown are from transformed cycle threshold values with a standard curve. There were no statistically significant effects due to treatments. Before quantitative reverse transcription PCR, synthesized cDNA was diluted $1 / 4$ (vol/vol) with DNase-RNase-free water in experiment 1 and diluted $1 / 3$ (vol/vol) in experiment 2 . These differences in dilution are reflected by the magnitude of the responses observed across most samples between both experiments. See Table 3 for description of genes.

tion factors such as v-myc myelocytomatosis viral oncogene homolog (MYC; Grandori et al., 2005), v-myc myelocytomatosis viral related oncogene, neuroblastoma derived ( $M Y C N$; Boon et al., 2001; Valentijn et al., 2005), tumor protein p53(TP53; Ginsberg et al., 1991), erythropoietin (EPO; Kolbus et al., 2003), and KIT ligand (KITLG; Kolbus et al., 2003) (Figure 2).
In addition, Ingenuity Pathway Analysis identified 21 out of 49 genes with no known co-regulation (Figure 2 ). These 21 transcripts with no known co-regulation plus $U X T$, which did not show co-regulation with the 21 genes, were used for further analysis. Addition of UXT was justified by previous observations, in which this gene was found to be a suitable ICG for use in 

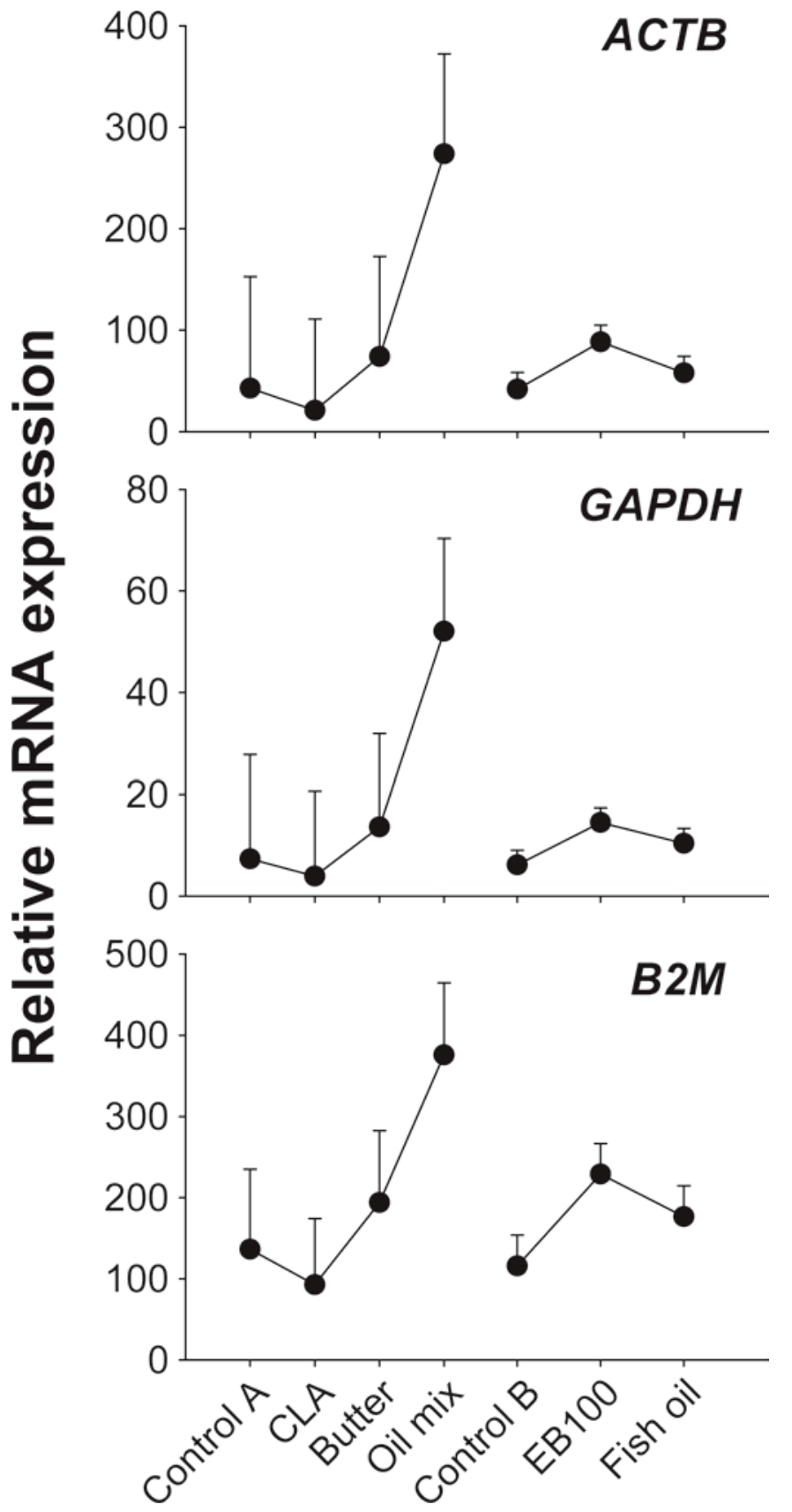

Figure 4. Expression patterns (raw quantitative reverse transcription PCR values after transformation of cycle threshold values using the standard curve) of $\beta$-actin $(A C T B)$, glyceraldehyde-3-phosphate dehydrogenase $(G A P D H)$, and $\beta$-2-microglobulin $(B 2 M)$ in the 2 experiments. There were no statistical effects of treatment. However, a tendency $(P=0.10)$ for treatment effects was observed in experiment 1 for $B 2 M$.

mammary tissue across multiple experimental conditions (Bionaz and Loor, 2007; Piantoni et al., 2008). Among these 22 genes, aquaporin 11 (AQP11), solute carrier family 35 member E2 (SLC35E2), gap junction protein beta 5 (GJB5), serine dehydratase-like ( $S D S L)$, FYVE RhoGEF and PH domain containing 5 (FGD5), and neuroglobin $(N G B)$ were rejected because of their low expression as verified with gel electrophoresis. In addition, we were unable to design appropriate primers for dead end homolog 1 (zebrafish) (DND1), family with sequence similarity 57, member A (FAM57A), PCF11, cleavage and polyadenylation factor subunit, homolog (Saccharomyces cerevisiae) (PCF11), protein tyrosine phosphatase, receptor type f polypeptide (PTPRF) interacting protein (liprin) alpha 3 (PPFIA3), and single-strand-selective monofunctional uracil-DNA glycosylase 1 (SMUG1). Last, 11 ICG were selected for qPCR analysis: COPS7A, CORO1B, DNAJC19, EIF3K, EMD, GOLGA5, GPR175, MARVELD1, MTG1, MRPL39, and UXT (see Table 3 for names and descriptions); qPCR also was run for $A C T B, G A P D H$, and B2M.

\section{ICG Expression Profile and Stability Evaluation}

Bionaz and Loor (2007) demonstrated that selection of reliable ICG based on a simple statistical analysis was not appropriate. In mammary tissue undergoing large changes in physiological state between prepartum and lactation (Bionaz and Loor, 2007; Tramontana et al., 2008), genes associated with milk component synthesis had a tremendous increase in abundance, diluting the relative mRNA concentration of stably expressed genes, which appeared to be downregulated after qPCR analysis. In the case of lipid supplementation, it is well established that the nature of dietary fat can elicit changes in mRNA of lipogenic genes (Shingfield and Griinari, 2007). Expression patterns of ICG (Figures 3 and 4) were suggestive of an absence of a significant dilution effect of stably expressed genes (i.e., ICG), as we did not observe significant differences between treatments. However, there was an apparent numerical decrease in expression of all ICG measured with the CLA treatment in experiment 1 as well as a numerical increase in expression due to feeding EB100 in experiment 2 . In addition, the statistical analysis uncovered a negative correlation between the 3 lipogenic genes and all ICG except B2M (Table 4). In experiment 2, all correlations were highly significant and the pattern between ICG and lipogenic genes followed the opposite trend (Figures 3 and 6). Among the measured lipogenic genes, FASN and $S C D$ were highly abundant in mammary tissue compared with all ICG (Table 2); thus, an increase in their expression might have affected apparent expression of ICG. Treatments in experiments 1 and 2 did not result in large effects of FASN and $S C D$ mRNA expression, which in part agrees with the behavior of all the ICG tested. Overall, a numerical dilution effect cannot be discounted but did not seem to be the case under conditions in the present studies. 
Table 4. Pearson correlations between mRNA expression of $A C T B, G A P D H$, and B2M with the raw values (i.e., nonnormalized) of lipogenic genes ${ }^{1}$ in experiments 1 and $2^{2}$

\begin{tabular}{|c|c|c|c|c|c|c|c|c|c|c|c|c|}
\hline \multirow[b]{2}{*}{ Gene } & \multicolumn{2}{|c|}{$A C A C A$} & \multicolumn{2}{|c|}{ FASN } & \multicolumn{2}{|c|}{$S C D$} & \multicolumn{2}{|c|}{$A C T B$} & \multicolumn{2}{|c|}{$G A P D H$} & \multicolumn{2}{|c|}{ B2M } \\
\hline & Exp. 1 & Exp. 2 & Exp. 1 & Exp. 2 & Exp. 1 & Exp. 2 & Exp. 1 & Exp. 2 & Exp. 1 & Exp. 2 & Exp. 1 & Exp. 2 \\
\hline GAPDH & -0.25 & -0.82 & -0.36 & -0.77 & -0.34 & -0.77 & 0.99 & 0.94 & & & & \\
\hline$B 2 M$ & -0.25 & -0.82 & -0.38 & -0.80 & -0.37 & -0.78 & 0.96 & 0.87 & 0.96 & 0.93 & & \\
\hline COPSYA & -0.27 & -0.79 & -0.31 & -0.68 & -0.28 & -0.76 & 0.01 & 0.80 & 0.02 & 0.85 & 0.05 & 0.78 \\
\hline CORO1B & -0.66 & -0.78 & -0.72 & -0.71 & -0.69 & -0.72 & 0.27 & 0.89 & 0.31 & 0.92 & 0.37 & 0.86 \\
\hline$E M D$ & -0.64 & -0.77 & -0.67 & -0.69 & -0.64 & -0.69 & 0.18 & 0.91 & 0.22 & 0.93 & 0.28 & 0.80 \\
\hline GOLGA5 & -0.36 & -0.71 & -0.38 & -0.57 & -0.37 & -0.66 & 0.21 & 0.70 & 0.24 & 0.78 & 0.33 & 0.76 \\
\hline$G P R 175$ & -0.51 & -0.76 & -0.49 & -0.70 & -0.50 & -0.73 & 0.05 & 0.84 & 0.09 & 0.89 & 0.18 & 0.84 \\
\hline$M A R V E L D 1$ & -0.56 & -0.78 & -0.56 & -0.76 & -0.56 & -0.71 & 0.02 & 0.91 & 0.06 & 0.93 & 0.10 & 0.86 \\
\hline MRPL39 & -0.57 & -0.79 & -0.59 & -0.72 & -0.60 & -0.78 & 0.25 & 0.89 & 0.29 & 0.92 & 0.37 & 0.87 \\
\hline$M T G 1$ & -0.44 & -0.63 & -0.40 & -0.56 & -0.41 & -0.58 & -0.05 & 0.76 & -0.01 & 0.76 & 0.10 & 0.68 \\
\hline$U X T$ & -0.59 & -0.80 & -0.56 & -0.73 & -0.54 & -0.79 & 0.17 & 0.88 & 0.20 & 0.91 & 0.29 & 0.89 \\
\hline
\end{tabular}

${ }^{1}$ Details of the genes are reported in Table 3.

${ }^{2}$ Significant correlations $(P<0.05)$ are in bold.

As expected, we observed greater mRNA expression of most ICG in control animals in experiment 2 (dilution 1:3, vol/vol) compared with controls in experiment 1 (dilution 1:4, vol/vol; Figures 3 and 4) because of the difference in cDNA dilution before qPCR (see Materials and Methods) between experiments. Exceptions were MARVELD1 and EIF3K. These 2 genes could be considered highly expressed in cows from experiment 1 , highlighting animal variation between experiments. The difference in the dilution of cDNA for qPCR analysis is not a limitation for testing the suitability of ICG using our approach for several reasons. First, the microarray data were generated using the same protocol, the same amount of cDNA for each sample, and the same reference RNA sample (Thering et al., 2007; Kadegowda et al., 2008), allowing the discovery of stably expressed genes across all animals tested. Second, the pairwise comparison method to select appropriate ICG takes care of any possible technical error such as differences in dilution of cDNA, which would be a limitation when using statistical differences as the sole ICG selection approach. Furthermore, when considering each experiment separately we did not observe a significant effect of any treatment on ICG qPCR data (Figure 3), except for a tendency of LCFA (i.e., oil mix, experiment 1) to increase $B 2 M$ mRNA $\mathrm{qPCR}$ data (i.e., $\mathrm{qPCR}$ data not normalized or data after $\mathrm{Ct}$ transformation with the standard curve). Despite the lack of significance, compared with control treatments there was a numerical decrease in qPCR data of all ICG tested when CLA was infused in experiment 1 and a numerical increase of all ICG with EB100 and fish oil in experiment 2. As discussed above, the use of "lack of significant treat- ment effect" is not an appropriate criterion to select suitable ICG. An increase or decrease of ICG mRNA expression due to a particular treatment can be caused solely by technical limitations. An example of this is the dilution effect previously discussed (Bionaz and Loor, 2007; Piantoni et al., 2008; Tramontana et al., 2008).

The pairwise comparison method using geNorm software was previously demonstrated to be adequate for selecting appropriate ICG across several experimental conditions in bovine and swine mammary tissue (Bionaz and Loor, 2007; Piantoni et al., 2008; Tramontana et al., 2008). The method defines gene stability (M) as the constancy of the expression ratio between 2 nonco-regulated genes across all samples tested. The more stable the expression ratio among 2 genes, the more likely that the genes are appropriate internal controls; that is, 2 ideal control genes should have an identical expression ratio in all samples regardless of experimental conditions, cell, or tissue type. The lower the $\mathrm{M}$ value, the higher the stability of expression ratio (Vandesompele et al., 2002). In addition, geNorm performs an analysis to determine the utility of including $>2$ genes for normalization by calculating the pairwise variation $(\mathrm{V})$ between the $\mathrm{NF}$ obtained using 2 genes (i.e., $\mathrm{NF}_{2}$ ) and the NF obtained using $2+1$ genes (i.e., addition of an extra ICG with lower stability ratio; $\left.\mathrm{NF}_{2+1}\right)$. A large decrease in the pairwise variation of $\mathrm{NF}_{\mathrm{n}+1}$ indicates that addition of the subsequent ICG (i.e., with lower M value) had a significant effect and should be included for calculation of the NF. Once the ICG with the lowest variation in expression ratio are selected, geNorm calculates the NF through the geometrical averaging of raw $\mathrm{qPCR}$ values of the selected ICG (i.e., qPCR data 

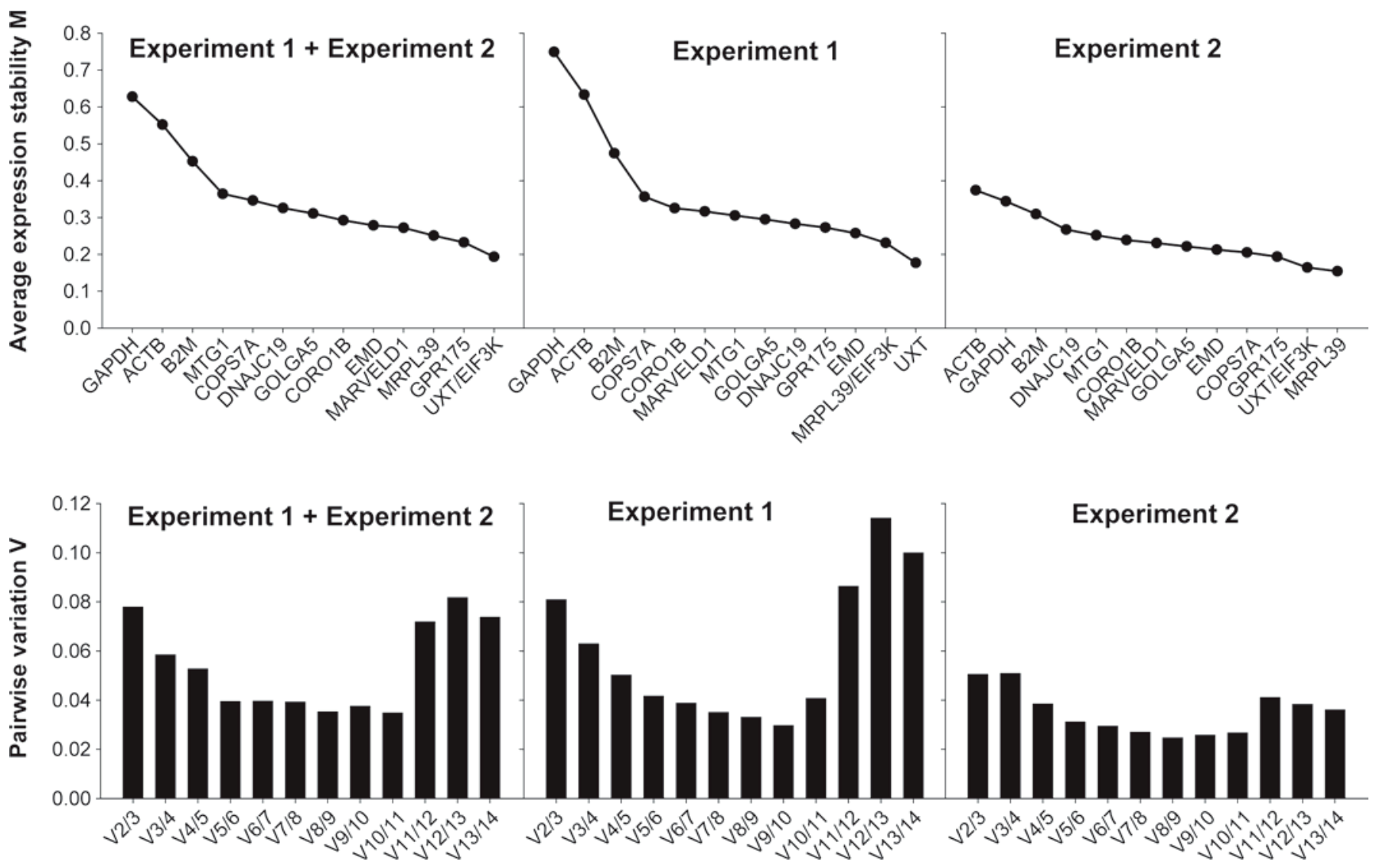

Figure 5. Top panels: stability of potential internal control genes (ICG) calculated via pairwise comparisons for individual and combined experiments. Genes in the x-axis are ranked from right to left based on pairwise ratio stability (M; lowest M denotes highest ratio stability). The ICG in the extreme left of the graph denote the genes with lowest expression ratio stability, calculated by the pairwise comparison with all the other genes among all samples. The ICG reported at the right of the graph represent the genes with the highest expression ratio stability among all genes. Bottom panels indicate determination of optimal ICG number for normalization for individual and combined experiments. Greater stability is denoted by a lower M value, whereas the optimal number of genes for calculating the normalization factor (NF) is denoted by a low pairwise variation $(\mathrm{V})$. In the bottom graph, y-axis denotes pairwise variation $\mathrm{V}(\mathrm{Vn} / \mathrm{n}+1)$ between the normalization factors $\mathrm{NFn}$ and $\mathrm{NFn}+1$. The lower the V, the higher the stability (i.e., reliability) of the calculated NF. The lowest V denotes the optimal number of genes that should be used to calculate the NF. However, a threshold of 0.15 was considered acceptable to Vandesompele et al. (2002), whereas Bionaz and Loor (2007) suggested a $\mathrm{V} \leq 0.10$. The $\mathrm{x}$-axis denotes the comparison between the use of the 2 or $2+1$ least stable genes to calculate the normalization factor; that is, V2/3 is the comparison between use of 3 versus 2 ICG to calculate the NF (see Vandesompele et al., 2002 for detailed explanation). See Table 3 for description of genes.

after transformation using the standard curve). Last, the resulting $\mathrm{NF}$ is used to normalize qPCR data from target genes (Figure 5).

Regardless of whether experiments were combined or analyzed separately, geNorm uncovered EIF3K, UXT, GPR175, and MRPL39 as the genes with the most stable expression ratio $(\mathrm{M} \leq 0.20)$ among those assessed. In contrast, $A C T B, G A P D H$, and $B 2 M$ were the genes with the least stable expression ratio $(M \geq 0.30)$ among those studied (Figure 5, top panels). When considering the 2 experiments combined, analysis would suggest using 11 ICG to calculate an optimal NF. However, use of 3 instead of 2 ICG (UXT and EIF3K) would decrease the variation of NF from 0.20 (Figure 5, top left panel) to 0.06 (Figure 5, bottom left panel). Vandesompele et al. (2002) suggested using a NF with variation $\leq 0.15$.
To increase reliability, Bionaz and Loor (2007) suggested use of NF with variation $\leq 0.10$. The level of variation obtained using 3 ICG to calculate the NF was clearly below the thresholds suggested. Considering this, and for all practical purposes, use of 3 genes with the most stable expression ratio to obtain the NF was highly reliable to normalize qPCR data from both experiments, as demonstrated below.

It is noteworthy that we observed large differences in the stability of expression ratio among ICG assessed between the 2 experiments. Experiment 1 was characterized by greater variation in stability, whereas experiment 2 was characterized by very high stability of expression ratio among ICG (Figure 5). Furthermore, in both experiments, the widely used ICG $(A C T B$, $G A P D H$, and B2M) had low stability of expression ratio 

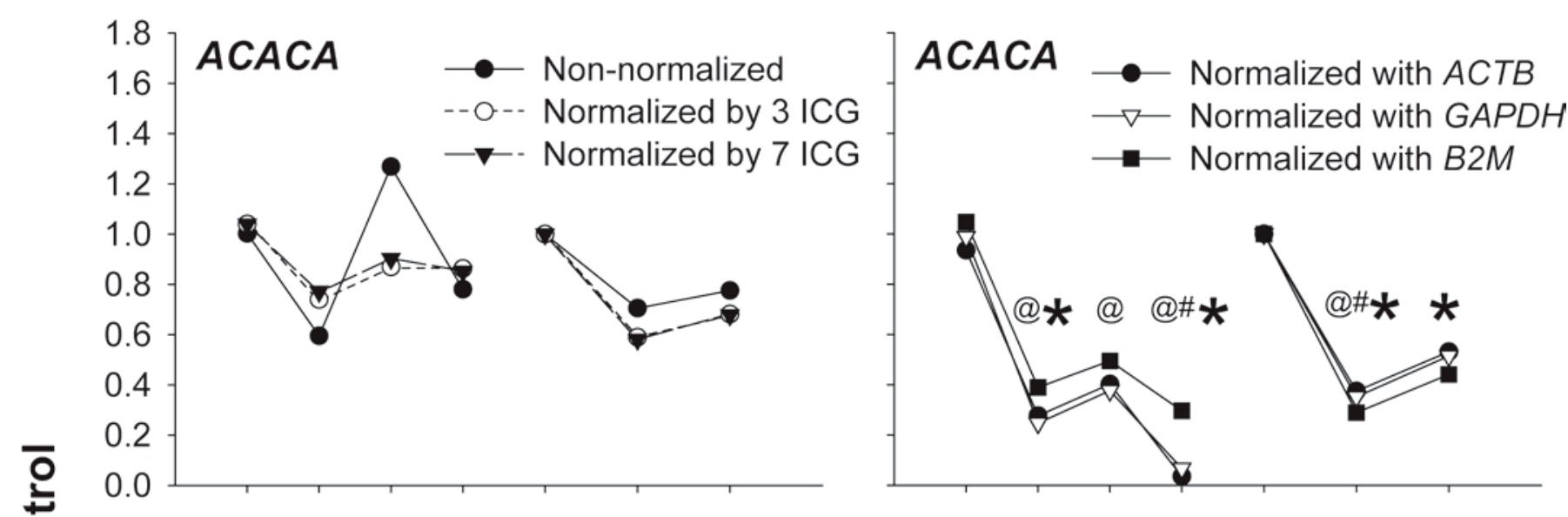

\section{FASN}

FASN
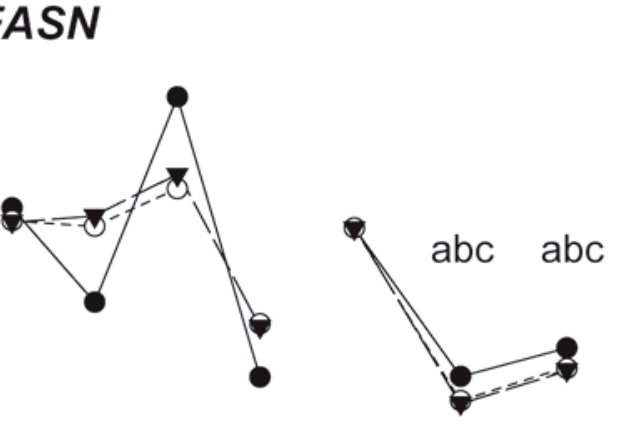

0.4

0.2

0.0

흥
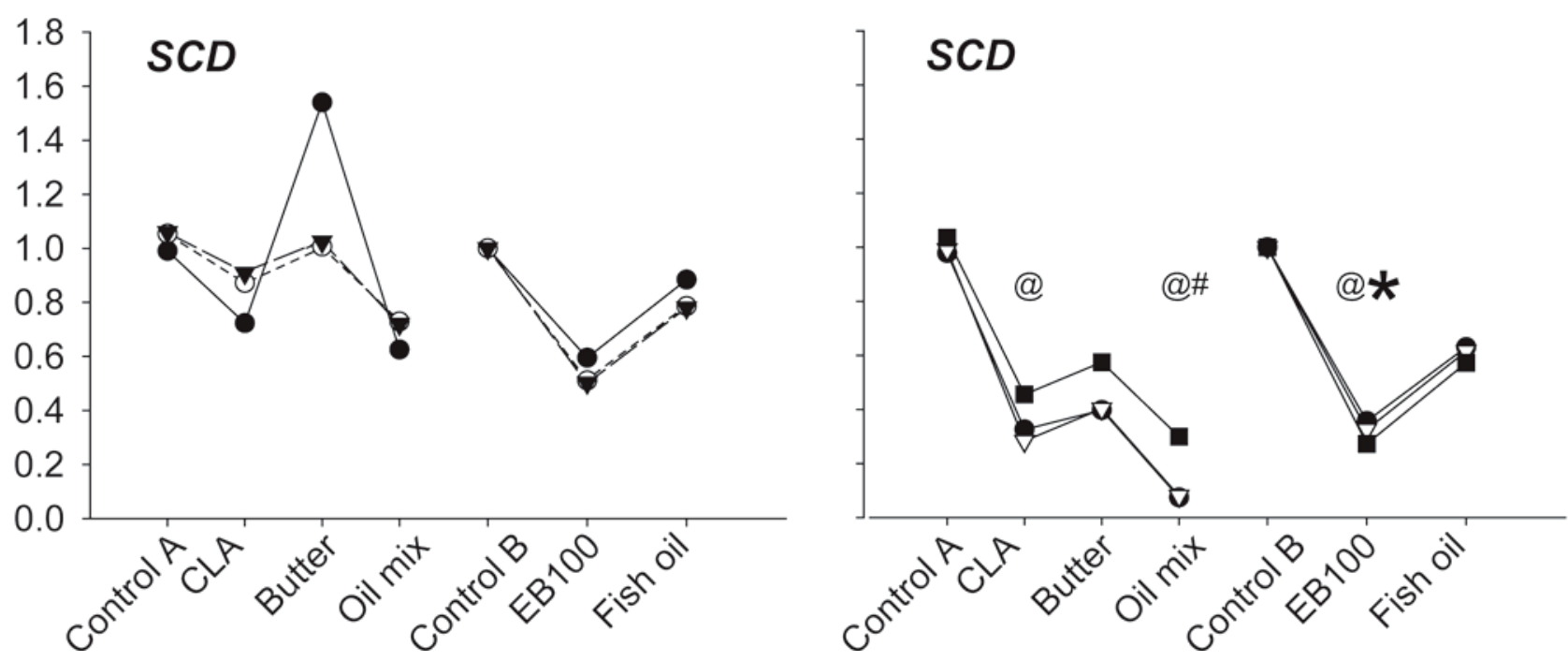

Figure 6. Left panels: Patterns of mammary tissue acetyl-CoA carboxylase- $\alpha$ ( $A C A C A)$, fatty acid synthetase $(F A S N)$, and stearoyl-CoA desaturase $(S C D)$ mRNA expression before and after normalization using normalization factors calculated with the geometrical mean of 3 or 7 most stable genes as suggested by geNorm analysis. Right panels: The same genes normalized by $\beta$-actin $(A C T B)$, glyceraldehyde-3-phosphate dehydrogenase $(G A P D H)$, and $\beta$-2-microglobulin $(B 2 M)$. Significant differences $(P<0.1)$ compared with controls are denoted by letters $[\mathrm{a}=$ nonnormalized; $\mathrm{b}=$ normalized with 3 internal control genes (ICG); $\mathrm{c}=$ normalized with 6 ICG] and symbols (\# = normalized with $A C T B$; $@$ $=$ normalized with $G A P D H ;{ }^{*}=$ normalized with $\left.B 2 M\right)$. 
and confirmed the microarray data (Figure 1). There was substantially more variation within and between treatments in the pattern of expression of those genes (Figure 4) compared with the selected ICG (Figure 3 ). This was most evident in experiment 1 compared with experiment 2 , as highlighted by a positive and significant correlation between ICG and $A C T B, G A P D H$, and $B 2 M$ in experiment 2. In experiment 1 the same correlations were not always positive and none were significant (Table 4). These observations go along with the larger data variation in experiment 1 and the lower data variation in experiment 2 , as discussed above.

\section{mRNA Expression of ICG and Lipogenic Genes}

We compared normalization of lipogenic genes using NF calculated by using 3 or 6 (i.e., when there was no added gain in stability; Figure 5, bottom left panel) ICG with the most stable expression ratio among samples to investigate any potential variation in $\mathrm{qPCR}$ outcome (Figure 6). Results suggested that use of 3 of the most stable genes among selected ICG would be appropriate to normalize gene expression data from bovine mammary tissue in lipid supplementation studies (Figure 6, left panels). We also evaluated the effect of normalization strategy between the 2 experiments. In experiment 1 , the variation was visually evident and the normalization approach did not increase the difference between treatments but rather tended to flatten the responses. In experiment 2, the normalization approach had a lesser effect but the effect of the 2 treatments in decreasing expression of FASN was found only when data were normalized.

Finally, we tested the effect of normalizing data using $A C T B, G A P D H$, and B2M. Normalization of lipogenic genes using any of these ICG completely changed the final results, with a consistently greater downregulation of expression across treatments (Figure 6, right panels) relative to the use of ICG with larger stability of expression ratio (Figure 6, left panels). In fact, if data were normalized by expression of $G A P D H$, results would indicate that CLA, oil mix, and EB100 negatively affected expression of the lipogenic genes. Normalization using B2M resulted in downregulation of $A C A C A$ with CLA and oil mix, whereas EB100 downregulated $A C A C A, F A S N$, and $S C D ; A C T B$ tended to artificially decrease expression of all 3 genes. Data clearly exemplify the effect of using unreliable ICG to normalize qPCR data.

\section{CONCLUSIONS}

Results from this study showed that expression of $B 2 M, G A P D H$, and $A C T B$ was highly variable across 2 studies representing 66 individual cow observations and 6 different lipid supplements. Analysis of expression ratio via geNorm software uncovered MRPL39, GPR175, UXT, and EIF3K as the genes with the most stable expression ratio among all samples in each experiment and, thus, suitable as ICG. Analysis also indicated that use of 3 ICG was most appropriate for calculating a normalization factor. Results also showed that ICG selected for one physiological or experimental condition may or may not be suitable for a different condition. For example, Bionaz and Loor (2007) as in the present study found $U X T$ as a suitable ICG for longitudinal studies of bovine mammary tissue during lactation. In contrast, MTG1, which was one of the ICG with the highest expression ratio stability relative to other ICG in studies of prepubertal bovine mammary development (Piantoni et al., 2008), had a low expression ratio stability value in the present study. Our analysis uncovered novel ICG for qPCR normalization that could be used in similar studies as alternatives to the less reliable $A C T B, G A P D H$, or $B 2 M$. We conclude that the geometric average of MRPL39, UXT, and EIF3K was ideal for normalization of mammary qPCR data in the 2 studies involving lipid supplementation of dairy cows. These 3 genes plus the additional 8 genes identified via microarray should be considered in future studies and appropriately tested for suitability using the proposed protocols.

\section{ACKNOWLEDGMENTS}

Financial support for the gene expression work was provided by the Cooperative State Research, Education and Extension Service, US Department of Agriculture, under project No. ILLU-538-307 and ILLU-538-391 (both to JJL).

\section{REFERENCES}

Ahnadi, C. E., N. Beswick, L. Delbecchi, J. J. Kennelly, and P. Lacasse. 2002. Addition of fish oil to diets for dairy cows. II. Effects on milk fat and gene expression of mammary lipogenic enzymes. J. Dairy Res. 69:521-531.

Baumgard, L. H., E. Matitashvili, B. A. Corl, D. A. Dwyer, and D. E. Bauman. 2002. trans-10, cis-12 conjugated linoleic acid decreases lipogenic rates and expression of genes involved in milk lipid synthesis in dairy cows. J. Dairy Sci. 85:2155-2163.

Bernard, L., C. Leroux, M. Bonnet, J. Rouel, P. Martin, and Y. Chilliard. 2005. Expression and nutritional regulation of lipogenic genes in mammary gland and adipose tissues of lactating goats. J. Dairy Res. 72:250-255.

Bionaz, M., and J. J. Loor. 2007. Identification of reference genes for quantitative real-time PCR in the bovine mammary gland during the lactation cycle. Physiol. Genomics 29:312-319.

Boon, K., H. N. Caron, R. van Asperen, L. Valentijn, M. C. Hermus, P. van Sluis, I. Roobeek, I. Weis, P. A. Voute, M. Schwab, and R. Versteeg. 2001. N-myc enhances the expression of a large set of genes functioning in ribosome biogenesis and protein synthesis. EMBO J. 20:1383-1393. 
Farke, C., H. H. Meyer, R. M. Bruckmaier, and C. Albrecht. 2008. Differential expression of $\mathrm{ABC}$ transporters and their regulatory genes during lactation and dry period in bovine mammary tissue. J. Dairy Res. 75:406-414.

Genome Browser Gateway. 2008. UCSC Genome Bioinformatics Site; geNorm. University of California Santa Cruz, CA. http://medgen. ugent.be/ judesomp/genorm/.

Ginsberg, D., F. Mechta, M. Yaniv, and M. Oren. 1991. Wild-type p53 can down-modulate the activity of various promoters. Proc. Natl. Acad. Sci. USA 88:9979-9983.

Glare, E. M., M. Divjak, M. J. Bailey, and E. H. Walters. 2002. betaActin and GAPDH housekeeping gene expression in asthmatic airways is variable and not suitable for normalising mRNA levels. Thorax 57:765-770.

Grandori, C., N. Gomez-Roman, Z. A. Felton-Edkins, C. Ngouenet, D. A. Galloway, R. N. Eisenman, and R. J. White. 2005. c-Myc binds to human ribosomal DNA and stimulates transcription of rRNA genes by RNA polymerase I. Nat. Cell Biol. 7:311-318.

Harvatine, K. J., and D. E. Bauman. 2006. SREBP1 and thyroid hormone responsive spot 14 (S14) are involved in the regulation of bovine mammary lipid synthesis during diet-induced milk fat depression and treatment with CLA. J. Nutr. 136:2468-2474.

Kadegowda, A. K. G., L. S. Piperova, P. Delmonte, and R. A. Erdman. 2008. Abomasal infusion of butterfat increases milk fat in lactating dairy cows. J. Dairy Sci. 91:2370-2379.

Kolbus, A., M. Blazquez-Domingo, S. Carotta, W. Bakker, S. Luedemann, M. von Lindern, P. Steinlein, and H. Beug. 2003. Cooperative signaling between cytokine receptors and the glucocorticoid receptor in the expansion of erythroid progenitors: Molecular analysis by expression profiling. Blood 102:31363146 .

Loor, J. J., H. M. Dann, R. E. Everts, R. Oliveira, C. A. Green, N. A. Guretzky, S. L. Rodriguez-Zas, H. A. Lewin, and J. K. Drackley. 2005. Temporal gene expression profiling of liver from periparturient dairy cows reveals complex adaptive mechanisms in hepatic function. Physiol. Genomics 23:217-226.

Loor, J. J., H. M. Dann, N. A. Guretzky, R. E. Everts, R. Oliveira, C. A. Green, N. B. Litherland, S. L. Rodriguez-Zas, H. A. Lewin, and J. K. Drackley. 2006. Plane of nutrition prepartum alters hepatic gene expression and function in dairy cows as assessed by longitudinal transcript and metabolic profiling. Physiol. Genomics $27: 29-41$

Loor, J. J., R. E. Everts, M. Bionaz, H. M. Dann, D. E. Morin, R Oliveira, S. L. Rodriguez-Zas, J. K. Drackley, and H. A. Lewin. 2007. Nutrition-induced ketosis alters metabolic and signaling gene networks in liver of periparturient dairy cows. Physiol. Genomics 32:105-116.

National Center of Biotechnology Information. 2008. http://www.ncbi. nlm.nih.gov/blast/Blast.cgi Accessed Jul. 10, 2008.
Peterson, D. G., E. A. Matitashvili, and D. E. Bauman. 2003. Dietinduced milk fat depression in dairy cows results in increased trans-10, cis-12 CLA in milk fat and coordinate suppression of mRNA abundance for mammary enzymes involved in milk fat synthesis. J. Nutr. 133:3098-3102.

Peterson, D. G., E. A. Matitashvili, and D. E. Bauman. 2004. The inhibitory effect of trans-10, cis-12 CLA on lipid synthesis in bovine mammary epithelial cells involves reduced proteolytic activation of the transcription factor SREBP-1. J. Nutr. 134:2523-2527.

Piantoni, P., M. Bionaz, D. E. Graugnard, K. M. Daniels, R. M. Akers, and J. J. Loor. 2008. Gene expression ratio stability evaluation in prepubertal bovine mammary tissue from calves fed different milk replacers reveals novel internal controls for quantitative polymerase chain reaction. J. Nutr. 138:1158-1164.

Piperova, L. S., B. B. Teter, I. Bruckental, J. Sampugna, S. E. Mills, M. P. Yurawecz, J. Fritsche, K. Ku, and R. A. Erdman. 2000. Mammary lipogenic enzyme activity, trans fatty acids and conjugated linoleic acids are altered in lactating dairy cows fed a milk fat-depressing diet. J. Nutr. 130:2568-2574.

Rudolph, M. C., M. C. Neville, and S. M. Anderson. 2007. Lipid synthesis in lactation: diet and the fatty acid switch. J. Mammary Gland Biol. Neoplasia 12:269-281.

Shingfield, K. J., and J. M. Griinari. 2007. Role of biohydrogenation intermediates in milk fat depression. Eur. J. Lipid Sci. Technol. 109:799-816.

Sorensen, B. M., E. Chris Kazala, G. K. Murdoch, A. F. Keating, C. Cruz-Hernandez, J. Wegner, J. J. Kennelly, E. K. Okine, and R. J. Weselake. 2008. Effect of CLA and other C18 unsaturated fatty acids on DGAT in bovine milk fat biosynthetic systems. Lipids 43:903-912.

Thering, B. J., D. E. Graugnard, P. Piantoni, R. L. Wallace, R. E. Everts, S. L. Rodriguez-Zas, H. A. Lewin, and J. J. Loor. 2007. Transcriptional regulation of mammary and adipose tissue gene expression in dairy cows fed a milk fat-depressing or milk fatenhancing diet. J. Dairy Sci. 90(Suppl. 1):83. (Abstr.)

Tramontana, S., M. Bionaz, A. Sharma, D. E. Graugnard, E. A. Cutler, P. Ajmone-Marsan, W. L. Hurley, and J. J. Loor. 2008. Internal controls for quantitative polymerase chain reaction of swine mammary glands during pregnancy and lactation. J. Dairy Sci. 91:3057-3066.

Valentijn, L. J., A. Koppen, R. van Asperen, H. A. Root, F. Haneveld, and R. Versteeg. 2005. Inhibition of a new differentiation pathway in neuroblastoma by copy number defects of $\mathrm{N}$-myc, Cdc42, and nm23 genes. Cancer Res. 65:3136-3145.

Vandesompele, J., K. De Preter, F. Pattyn, B. Poppe, N. Van Roy, A. De Paepe, and F. Speleman. 2002. Accurate normalization of realtime quantitative RT-PCR data by geometric averaging of multiple internal control genes. Genome Biol. 3(7):RESEARCH0034. 